\title{
Alcoholic vagal neuropathy: recovery following prolonged abstinence
}

\author{
ETH TAN, RH JOHNSON, DG LAMBIE, EA WHITESIDE \\ From the Dean's Research Group, Wellington Clinical School of Medicine, Wellington Hospital, Wellington, \\ New Zealand.
}

SUMMARY Cardiac vagal reflexes were studied in 11 alcoholic subjects, 1 to 6 weeks after withdrawal and again after up to 27 months of continued abstinence. On initial investigation six subjects had vagal neuropathy. On the second occasion only two subjects had vagal neuropathy and significant improvement was seen in the total patient group with regard to heart rate responses to standing, Valsalva's manoeuvre and atropine infusion. Vagal neuropathy in alcoholics may be reversible with abstinence and/or improved nutrition.

Chronic alcohol abuse may cause parasympathetic nerve damage. Novak and Victor ${ }^{1}$ described four alcoholics who had dysphonia and dysphagia and confirmed the destruction of the vagus nerve in three of these patients at post-mortem examinations. In previous studies we showed by physiological testing that alcoholics may show abnormal parasympathetic control of the heart ${ }^{2}$ and of the pupil. ${ }^{3}$ This may be of clinical importance. Autonomic neuropathy is associated with high mortality in patients with diabetes. ${ }^{4}$ Also, autonomic neuropathy may be a factor in impotence in alcoholic patients. ${ }^{5}$ This report describes a sequential study on a group of alcoholic patients to assess the course of vagal neuropathy with continued abstinence.

\section{Subjects}

Eleven alcoholics were studied. They had a mean age of $55 \cdot 2 \mathrm{yr}$ (range 47-62 yr) and, when first studied, a mean period of abstinence of 3.4 weeks (range 1.4-6 weeks). They had previously been drinking 100-300 g ethanol daily over a period of 10 years or more. Seven healthy male control subjects with a mean age of 45.9 yr (range 38-50 yr) also participated in the study.

\section{Methods}

Physiological testing of vagal control of the heart was carried out as follows:

Address for reprint requests: Prof RH Johnson, Wellington Clinical School of Medicine, Wellington Hospital, Private Bag, New Zealand.

Received 30 May 1984. Accepted 16 June 1984 (a) Heart rate responses to standing ("30/15" ratio)

The subject lay supine and basal heart rate was recorded on an electrocardiogram (ECG). The subject was asked to stand up quickly. The longest $R-R$ interval, around the 30 th beat after standing and the shortest $R-R$ interval around the 15 th beat after standing were expressed as the $30: 15$ ratio. The normal range for this ratio was taken to be $\geqslant 1 \cdot 04 .^{\circ}$

(b) Heart rate response to Valsalva's manoeuvre

The subject was seated, and blew for 20 seconds into a mouthpiece attached to an anaeroid manometer, a pressure of $40 \mathrm{mmHg}$ being maintained. The longest $R-R$ interval after the manoeuvre and the shortest $R-R$ interval during the manoeuvre were measured from the ECG and expressed as the Valsalva ratio. A Valsalva ratio of $\geqslant 1 \cdot 21$ was taken as normal.'

(c) Heart rate responses to deep breathing

The subject breathed deeply at a rate of 6-8 breaths/min for one min, while sitting. The variation in heart rate was calculated from the average maximum $R-R$ interval and the average minimum $R-R$ interval during expiration and inspiration respectively. Interpretation of the results was based on an age-dependent normal range described by other workers. ${ }^{8}$

\section{(d) Heart rate response to atropine}

The subject lay supine. Atropine sulphate $(1.8 \mathrm{mg})$ was administered intravenously at a rate of $0.6 \mathrm{mg} / \mathrm{min}$, with a one minute interval between each $0.6 \mathrm{mg}$ dose. The maximum change in heart rate from basal was measured. A change of $>20$ beats $/ \mathrm{min}$ was taken as normal. The tests of vagal function were carried out in all alcoholic subjects at the beginning of the study and again after a period (4-27 months) of continued abstinence. For the control subjects, the vagal function tests were similarly repeated $9-30$ 
months after first assessment. Statistical comparisons of results between the first and the second study were made using Wilcoxon's signed ranks test for related samples.

\section{Results}

Six alcoholic subjects had evidence of vagal neuropathy during the first assessment, as determined by abnormalities in two or more tests (patients 6-11, table). The other five alcoholics (patients 1-5) had no significant evidence of vagal neuropathy. The results of both studies for all the patients are shown in the table. Significant difference were found between the first and the second study for the Valsalva ratio ( $p<0.01), 30: 15$ ratio $(\mathrm{p}<0.01)$ and heart rate response to atropine $(\mathrm{p}<$ $0.02)$ for the eleven alcoholic subjects. The mean resting heart rate fell from $79.4 \pm 13.7$ (SD) at the time of first study to $64.5 \pm 6.1 \mathrm{beats} / \mathrm{min}$ at the time of the second study $(p<0.01)$.

The results of the vagal function tests for the seven control subjects on the first and second occasions are presented in the table. There were no significant differences between the first and the second study for any test.

\section{Discussion}

Alcoholics may suffer central damage to autonomic pathways resulting in hypothermia, and peripheral autonomic involvement may result in sweating loss or disorder of parasympathetic control of the heart and pupil, ${ }^{3}$ although orthostatic hypotension is rarely a feature of chronic alcoholism. ${ }^{.10}$ Six of eleven alcoholic subjects in this study had evidence of vagal neuropathy on initial investigation. On follow-up investigation, after 4-27 months of continued abstinence, only two patients $(7,97)$ had definite evidence of vagal neuropathy (abnormalities in two or more tests) and for the total group of alcoholic patients there were significant increases in the heart rate responses to standing, Valsalva's manoeuvre and atropine. Thus there is evidence of recovery of vagal function with prolonged abstinence and improved nutrition at least in some alcoholic patients. This possibility of reversibility of autonomic neuropathy is in line with pathological evidence. Histological examination of myelinated fibres of the sympathetic chains of alcoholic patients showed short internodes which were consistent with either Wallerian or "dying back" degeneration followed by partial regeneration."

Nutritional factors rather than a direct toxic effect

Table Results of tests of vagal function in alcoholic and control patients on initial (1) and follow-up (2) investigation. Alcoholic patients were initially studied 1-6 weeks after withdrawal, and then again after 4-27 months of continued abstinence

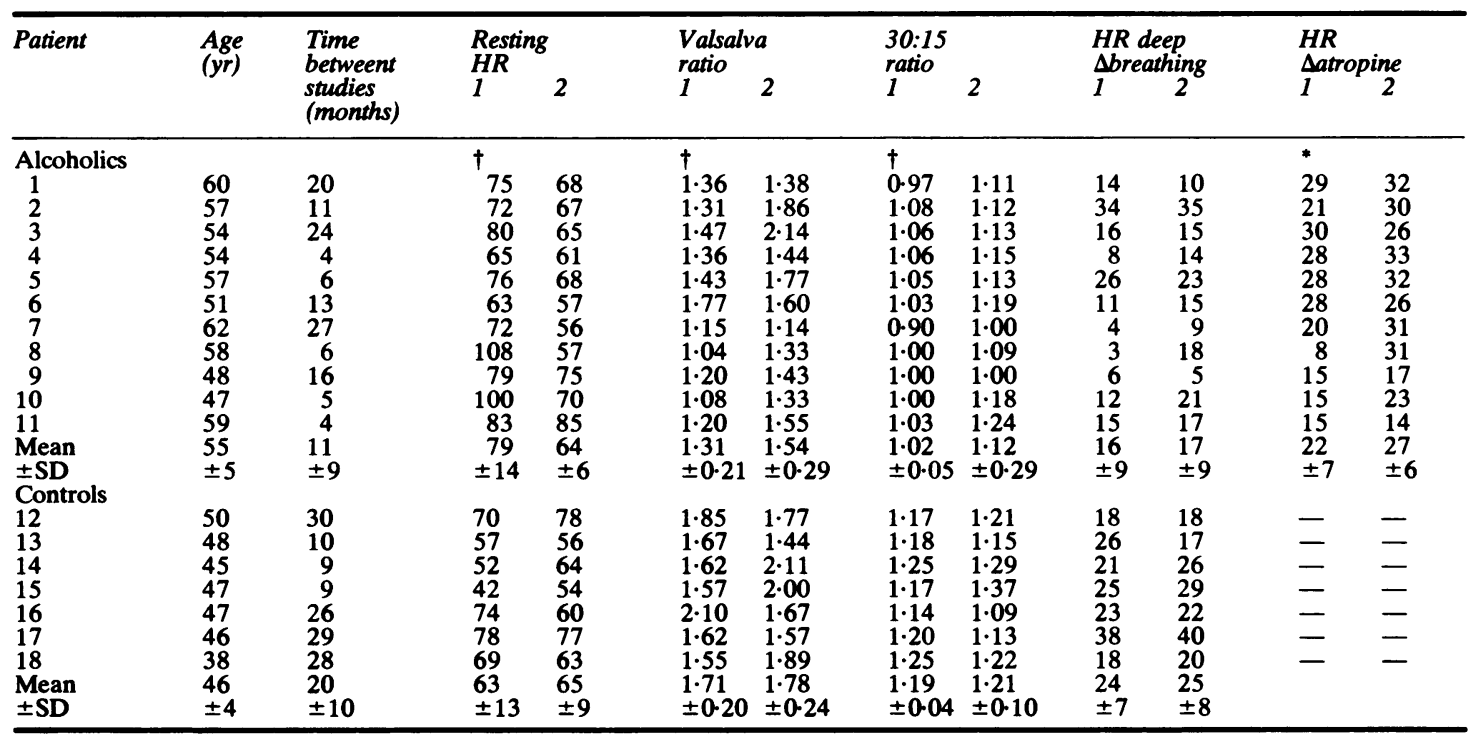

*significant difference between first and second studies $\mathrm{p}<0.02$

†significant difference between first and second studies $\mathrm{p}<0.01$ 
of alcohol are generally regarded as most important in the pathogenesis of alcoholic peripheral neuropathy. ${ }^{1213}$ The patients in this study were under institutional care for several weeks after withdrawal and received vitamin and mineral supplements under supervision. Recovery of vagal function has previously been described in new diabetic patients, initially depressed heart rate responses to deep breathing becoming normal within a few weeks of the start of insulin therapy. ${ }^{14}$ is Also, reversibility of abnormalities of autonomic innervation of the pupil has been described in diabetics with improved metabolic control. ${ }^{16} \mathrm{~A}$ good diet is likely to protect against the development of vagal neuropathy in alcoholics, as has previously been described for peripheral neuropathy. ${ }^{11}$

We are grateful to the Alcoholic Liquor Advisory Council and the Maurice and Phyllis Paykel Trust for financial support.

\section{References}

' Novak DJ, Victor M. The vagus and sympathetic nerves in alcoholic polyneuropathy. Arch Neurol 1974;30:273-84.

2 Duncan G, Johnson RH, Lambie DG, Whiteside EA. Evidence of vagal neuropathy in chronic alcoholics. Lancet 1980; 2:1053-7.

${ }^{3}$ Tan ETH, Lambie DG, Johnson RH, Whiteside EA. Parasympathetic denervation of the iris in alcoholics with vagal neuropathy.J Neurol Neurosurg Psychiatry 1984;47:61-4.

${ }^{4}$ Ewing DJ, Campbell IW, Clarke BF. Mortality in diabetic autonomic neuropathy. Lancet 1976;1:601-3 s Tan ETH, Johnson RH, Lambie DG, Vijayasenan ME, Whiteside EA. Erectile impotence in chronic alcoholics. Alcoholism 1984;8:297-301.

${ }^{6}$ Ewing, DJ, Cambell IW, Murray A, Neilson JMM, Clarke BF. Immediate heart-rate response to standing: simple test for autonomic neuropathy in diabetes. Br Med J 1978; 1:145-7.

${ }^{7}$ Ewing DJ, Campbell IW, Burt AA, Clarke BF. Vascular reflexes in diabetic autonomic neuropathy. Lancet 1973;2:1354-6.

${ }^{8}$ Wieling W, van Brederode JFM, de Rijk LG, Borst C, Dunning AJ. Reflex control of heart-rate in normal subjects in relation to age: a data base for cardiac vagal neuropathy. Diabetologia 1982;22:163-6.

9 Johnson RH, Spalding JMK. Disorders of the Autonomic Nervous System. Oxford: Blackwell, 1974.

10 Johnson RH, Lambie DG, Spalding JMK. Neurocardiology. London: Saunders, 1984.

" Walsh JC, McLeod JG. Alcoholic neuropathy. An electrophysiological and histological study. J Neurol Sci 1970;10:457-69.

${ }_{12}$ Appenzeller O, Kornfeld M. Myelinated fibres in the human paravertebral sympathetic chain; quantitative studies on white rami communicantes. J Neurol Neurosurg Psychiatry 1973;36:777-85.

${ }^{13}$ Behse F, Buchthal F. Alcoholic neuropathy: clinical, electrophysiological and biopsy findings. Ann Neurol 1977;2:95-110.

${ }^{14}$ Scott J, Lloyd-Mostyn RH. Acute autonomic dysfunction in diabetic ketoacidosis. Lancet 1976; 1:590.

${ }^{15}$ Fraser DM, Campbell IW, Ewing DJ, Murray A, Neilson JMM, Clarke BF. Peripheral and autonomic nerve function in newly diagnosed diabetes mellitus. Diabetes 1977;26:546-50.

${ }^{16}$ Hreidarsson AB. Acute, reversible autonomic nervous system abnormalities in juvenile insulin-dependent diabetes. Diabetologia 1981;20:475-81. 